\section{Vaginal Delivery during Extracorporeal Membrane Oxygenation: A Management Strategy}

Extracorporeal membrane oxygenation (ECMO) is being used with increasing frequency to support patients suffering from severe cardiac or respiratory failure. In pregnancy, ECMO has resulted in favorable maternal and fetal outcomes. ${ }^{1}$ However, there is a paucity of information regarding ECMO management in the peripartum period, including the ideal method of delivery. A case series of four patients describes 100 per cent survival of the mother and fetus where delivery was performed when the patients were on ECMO. ${ }^{2}$ In all of these cases, delivery was performed via cesarean section. Further investigation has revealed that all current information available in regard to this topic describe delivery via cesarean section only. ${ }^{1,3,4}$ Here, we describe a case in which a vaginal delivery was successfully performed when on ECMO, without significant blood loss or circuit complication. We describe our management strategies regarding maternal anticoagulation pre- and postvaginal delivery.

In June 2016, a 30-year-old G8P2052 female at $30 \mathrm{w} 4 \mathrm{~d}$ presented with hypoxic respiratory failure requiring mechanical ventilation, complicated by barotrauma and resultant pnuemomediastinum and subcutaneous emphysema. To reduce peak inspiratory pressure, improve oxygenation, and reduce hypercapnia, the patient was placed on veno-venous ECMO and subsequently placed on rest ventilator settings. Flow rates of 4 to $4.5 \mathrm{~L} / \mathrm{min}$ were achieved and the sweep was titrated to $\mathrm{PaCO}_{2}$ between 30 and $35 \mathrm{mmHg}$.

On ECMO day 1, the patient developed vaginal bleeding. Obstetric examination revealed a completely dilated cervix and bulging membranes. Heparin was held and blood products were made available at

Address correspondence and reprint requests to Anthony Charles, M.D., M.P.H., Department of Surgery, University of North Carolina at Chapel Hill, 4008 Burnett Womack Building, CB 7228, Chapel Hill, NC 27599. E-mail: anthchar@med.unc.edu. bedside. Amniotomy was performed and fetal decelerations to 90 beats/minute were noted on cardiotocography. Operative delivery via forceps was performed 60 minutes after heparin cessation; rectal misoprostol and a fibrinolytic agent (Amicar $1 \mathrm{~g}$ ) were administered after placental delivery. The uterus responded to intravenous Pitocin and fundal massage. The estimated blood loss for the procedure was $500 \mathrm{~mL}$, the upper limits of normal for vaginal delivery. The patient remained hemodynamically stable throughout the delivery and did not require transfusion of blood products. Heparin infusion was restarted four hours after delivery (held for five hours total) (see Fig. 1). Inspection of the ECMO circuit and oxygenator did not reveal any visible thrombus.

ECMO is a well-established modality for patients with hypoxic respiratory failure who have failed maximal conventional ventilation strategies. It has been used successfully in pregnancy, with maternal and fetal survival reported at 80 and 70 per cent, respectively. ${ }^{1}$ Although delivery of the fetus is deferred when possible, there are numerous reports of successful caesarean delivery when on ECMO. ${ }^{1-4}$ Strategies for anticoagulation during operative intervention on ECMO have been outlined in earlier reports. ${ }^{1}$ However, no data exist regarding vaginal delivery on ECMO or optimal anticoagulation strategy.

Our outlined anticoagulation strategy (Fig. 1) allowed for a successful operative vaginal delivery without significant maternal hemorrhage or circuit thrombotic complications after spontaneous labor when on ECMO. This is the first documented case of vaginal delivery with concomitant ECMO support. Our experience can provide anticoagulation guidance for other centers treating similar patients. The option for vaginal delivery rather than caesarean section must be explored when meeting obstetric indication.

Staci Aubry, M.D. Rebecca Brown, M.D. Emily Newton, M.D. Anthony Charles, M.D., M.P.H. 


\section{Timeline of Events - ECMO Day 1}

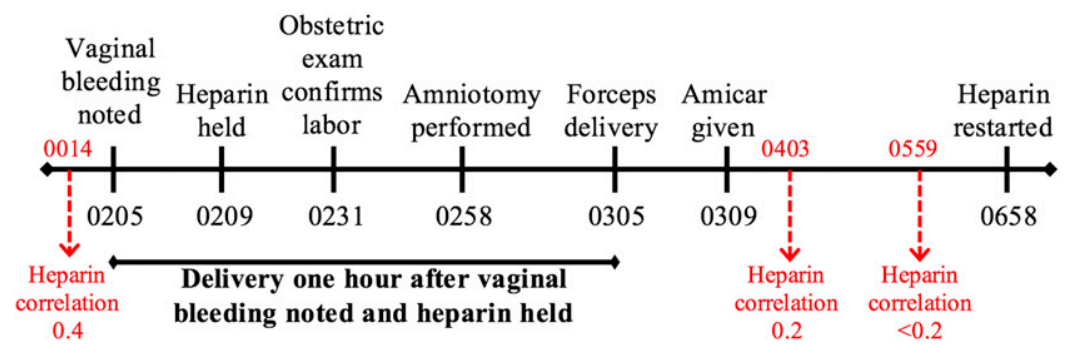

Heparin held for a total of five hours
FIG. 1. Timeline of peripartum events and associated anticoagulation strategy in our gravid patient requiring ECMO who went into spontaneous labor on ECMO day 1.

\section{Department of Surgery \\ University of North Carolina at Chapel Hill \\ Chapel Hill, North Carolina}

\section{REFERENCES}

1. Sharma NS, Wille KM, Bellot SC, et al. Modern use of extracorporeal life support in pregnancy and postpartum. ASAIO J 2015;61:110-4.
2. Morsolini M, Sciacca S, Panarello G, et al. Delivery during ECMO: a single-center case series. J Heart Lung Transplant 2017; 36:S333-4.

3. Lysenko L, Zaleska-Dorobisz U, Blok R, et al. A successful cesarean section in a pregnant woman with $\mathrm{A}(\mathrm{H} 1 \mathrm{~N} 1)$ influenza requiring ECMO support. Kardiochir Torakochirurgia Pol 2014;11:216-9.

4. Agerstrand C, Abrams D, Biscotti M, et al. Extracorporeal membrane oxygenation for cardiopulmonary failure during pregnancy and postpartum. Ann Thorac Surg 2016;102:774-9. 